\title{
THE ROLE OF STRESS CONGENTRATION IN SLAB AVALANCHE RELEASE
}

\author{
By R. A. Sommerfeld \\ (U.S. Forest Service, Rocky Mountain Forest and Range Experiment Station,* \\ Fort Collins, Colorado 8052 I, U.S.A.)
}

\begin{abstract}
Slab avalanches are shown to be released by brittle fracture. An analogy is drawn in which the snow-pack is considered to be a macroscopic, molecular model of glass. The analogy is examined qualitatively from two viewpoints: the Griffith fracture criterion, and stress concentration theory. The details of fracture propagation in a layered snow-pack are explained by means of stress concentration theory, and many details of slab avalanches are shown to be consistent with the proposed mechanism. The significance of various fracture surface markings is pointed out.
\end{abstract}

RÉsumÉ. Le rôle de la concentration des contraintes dans le déclenchement d'une avalanche en plaque. Les plaques d'avalanches sont déclenchées par fracture. On établit une analogie entre la couverture de neige qui est considérée être un modèle macrocospique et moléculaire de verre. On examine qualitativement cette analogie d'un double point de vue: le critère fracture de Griffith, et la théorie de la concentration des contraintes. Les détails de propagation de la fracture dans une couverture de neige stratifiée sont expliqués au moyen de la théorie de la concentration des contraintes et on montre que nombre de détails d'avalanches en plaque sont compatibles au mécanisme proposé. On fait remarquer la signification de plusieurs marques en surface fracturée.

Zusammenfassung. Die Rolle der Spannungskonzentration bei der Auslösung von Schneebrettern. Die Auslösung von Schneebrettern wird auf Abriss-Brüche zurückgeführt. In Analogie wird das Schneepaket als makroskopisches, molekulares Modell von Glas betrachtet und so qualitativ unter zwei Gesichtspunkten geprüft: Dem Bruch-Kriterium von Griffith und der Spannungskonzentrationstheorie. Die Einzelheiten der Bruchfortpflanzung in geschichtetem Schnee werden mit Hilfe der Spannungskonzentrationstheorie erklärt, wobei sich viele Übereinstimmungen zwischen einem Schneebrett und dem vorgeschlagenem Mechanismus ergeben. Auf die Bedeutung unterschiedlicher Merkmale der Bruchfläche wird hingewiesen.

\section{Introduction and Previous Theory}

Avalanches may be generally divided into two types: (I) loose snow slides, (2) slab avalanches. Slab avalanches exhibit a fracture line and therefore appear to have a unique release mechanism. The usual distinction between hard and soft slabs is irrelevant in a discussion of release mechanisms, since the distinction depends on the action of the snow after release.

All of the detailed mechanisms of avalanche release which have been proposed have emphasized the initial collapse of an internal weak layer. Haefeli (r942, r963) speaks of the shear fracture of a weak layer, and Bucher (1947, 1948) proposed a stability index of the ratio of shear strength to shear stress. Roch ( 1966 ) lists as possible mechanisms, in apparent order of importance: (I) tensile fracture at the crest of an avalanche path, (2) shear fracture of the borders of a snow-pack, (3) shear fracture of a weak layer underlying a snow-pack, and (4) compressive collapse of the lower part of a snow-covered slope, but he does not develop a detailed mechanism.

Jaccard (I966) emphasizes the properties of an internal weak layer as critical for the stability of a snow field. He states "Thus, it appears in the majority of cases that the determining region for stability is the base, the periphery coming into play only when a critical state of rupture is approached at the ground ...".

Bradley ( 1966 ) and Bradley and Bowles (1967) take the position that most avalanches are initiated by the compressive collapse of a weak layer in the snow-pack. This is different from Roch's compressive collapse (number 4, above) since it may occur anywhere on the slope, although it would be most likely at the foot of an avalanche path where the compressive stress is highest. They propose as a stability index, the ratio of the compressive strength to the load.

${ }^{*}$ Central headquarters maintained in cooperation with Colorado State University, Fort Collins, Colorado,
U.S.A. 
Moskalev (1967) develops a stability factor for the prediction of avalanches which includes the factors snow strength under constant load, anchorage at the circumference, filtration of water, and curvature of the slope. He emphasizes the shearing of a weak internal layer.

It should be possible to find avalanches which are released by any plausible mechanism because of the large variation in important factors among avalanches.

Serious objections can be raised to the idea that the failure of an internal layer is the most important mechanism of avalanche release. Both Bucher's (1947, r948) and Bradley and Bowles' ( 1967 ) stability indexes have been calculated from measurements on many avalanches. These calculations show that the large majority of avalanches involve snow layers with stability indexes (ratios of strength to stress) greater than I. Although these calculations may contain errors of unknown magnitude, at face value they show that most avalanches should have been stable under assumptions of the proposed stability index.

Another objection arises from the common observation of avalanches which do not fall immediately on the formation of visible tension cracks. "Hang fire" avalanches are delayed for as long as several minutes. In some instances, tension cracks are formed but no avalanche is released. If in these cases an internal layer had most of its cohesion destroyed by shear or compressive failure, there should be nothing to hold the snow on the slope following fracture at the periphery of the pack.

A third serious objection concerns the artificial release of avalanches. If the failure of an internal layer were the most common release mechanism, then the most efficient place for an explosive charge would be the middle or bottom of the slope. However, most workers state that avalanches are released most efficiently by a charge placed at the most convex portion of the hill where tensile stresses are highest.

Unpublished experiments (personal communication from R. M. Stillman) have shown that explosives placed on the surface of the snow at the fracture line are much more effective in releasing avalanches than explosives placed below the surface, at the weak layer.

A minor point is that skiing is often used to release small avalanches, while boot packing is used to stabilize a slope. If the release mechanism involves the collapse of an internal layer, one would predict that the higher loading on a boot print should be more efficient in initiating an avalanche than a ski track with a much lower specific loading.

These objections do not rule out internal failure mechanisms. They do cast some doubt on their importance, however, and show that it would be profitable to develop different hypotheses about release mechanisms which can then be used as alternatives in interpreting field evidence. Because of the complexity of the snow-pack, it is unlikely that a single definitive experiment can be designed but rather, the decision among mechanisms must be made on the basis of the preponderance of observation.

\section{Snow as a Brittle Material}

Snow is described as a visco-elastic material, and under high stress rates it acts as an almost ideal brittle material (Kinosita, I967). In slab avalanches, the tension fracture satisfies the brittle fracture criterion of little plastic deformation during rupture (Fig. I) that is, the pieces could be fitted back together.

These facts suggest that some of the extensive work in brittle fracture might be applied to snow. Two important results on brittle fracture are Griffith's (I92 I) theory for elastic cracks and the theories concerning stress concentration.

Griffith's theory states that a crack will propagate when the elastic energy released by the infinitesimal extension of a sharp crack is equal to or greater than the specific surface energy of the newly formed surfaces. The minimum fracture stress is given by $\sigma_{0}=(2 \gamma E / \pi c)^{\mathrm{I} / 2}$ where $\gamma$ is the specific surface energy, $E$ is Young's modulus, and $c$ is the crack length (McClintock and Argon, I966, p. 49o). It is readily seen that, since the fracture stress decreases with crack 
size, the crack will be self-propagating once it reaches a critical length, if the stress remains constant. The specific surface energy, $\gamma$, is the energy required to form a unit (macroscopic) surface of snow (not to be confused with the surface energy of ice).

This particular feature easily explains the observation that some snows with very low strength can exhibit the brittle fracture associated with slab avalanches. One of the most impressive scenes in the U.S. Forest Service training film "Snow avalanches" shows a whole slope shattering like a piece of glass when a charge is detonated. E. R. LaChapelle (personal communication) states that this snow was good, deep powder that would not support a man on skis. Thus, available elastic energy must have been very low; but since the density was very low $\left(\approx \mathrm{I}\right.$ oo $\left.\mathrm{kg} \mathrm{m}^{-3}\right)$, the number of bonds per unit area and thus the specific surface

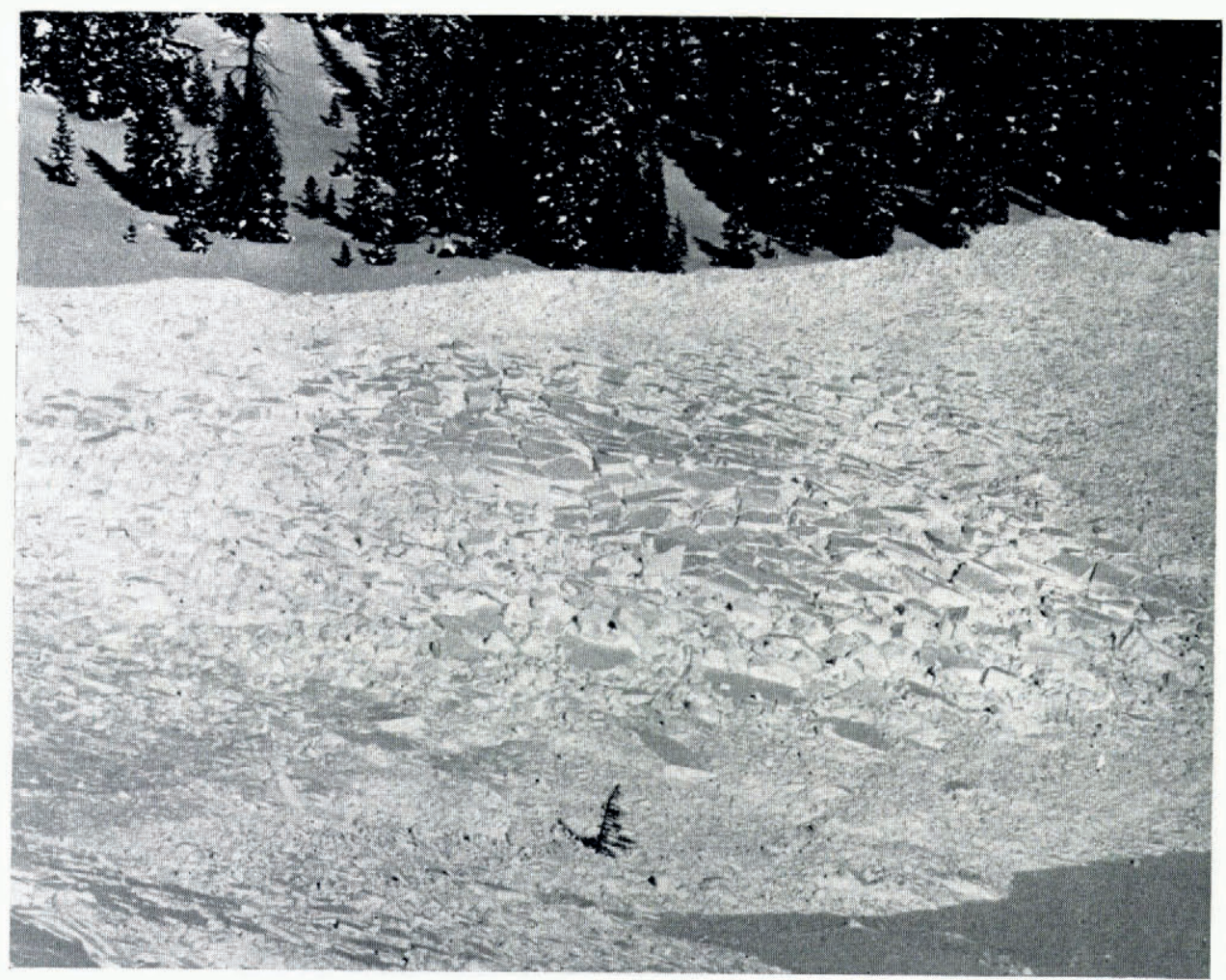

Fig. I. The "jigsaw-puzzle" fit which characterizes the brittle fracture of snow. (U.S. Forest Service photograph.)

energy, was also very low, and a crack could propagate once it was started. It is known that snows of densities to $400 \mathrm{~kg} \mathrm{~m}^{-3}$ can exhibit brittle fracture (Kinosita, I967). Thus, snows of a very wide range of densities and strengths can exhibit brittle fracture, the requirement being enough bonding so that the snow acts as a coherent material. By definition slab avalanches satisfy this criteria, after the fact, since they exhibit a fracture line.

A different viewpoint of brittle fracture involves the concept of stress concentration. In this theory, the fracture is idealized as a notch* with a length $c$ and a root radius $a$ (Fig. 2). This is perhaps a more realistic approximation than the sharp crack in Griffith's theory, since

* In fracture mechanics, a crack is infinitely sharp while a notch has a radiused end (root). It is not known, at present, if this distinction is important in snow fracture. 
the root radius $a$ would probably correspond to the average pore radius. When a notch is formed, the stress must be concentrated in the remaining material. Elastic analyses show stress concentrations (Fig. 2), with a very high concentration of tensile stress at the root of the notch. The tensile stress concentration at the notch root is given approximately by

$$
\frac{\sigma_{\max }}{\sigma_{\text {nom }}}=\mathrm{I}+2\left(\frac{c}{a}\right)^{\mathrm{I} / 2}
$$

where $\sigma_{\max }$ is the stress at the notch root, $\sigma_{\text {nom }}$ is the average stress in the material (McClintock and Argon, I966, p. 413). If, for example, the notch length is $100 \mathrm{~mm}$, and the root radius (the average pore radius) is $0.2 \mathrm{~mm}$, then the stress concentration factor will be about $5^{0}$. It is obvious that if the tensile stress is high enough to start a notch, the notch will easily propagate.

Also, for any stress there is a critical notch length such that larger notches will propagate. Thus, there is a range of stresses where the normal flaws in the snow are not large enough to propagate a fracture, but where the notch formed by a ski track or caused by explosives will be large enough to propagate. This is the stress range wherein artificial release is effective.
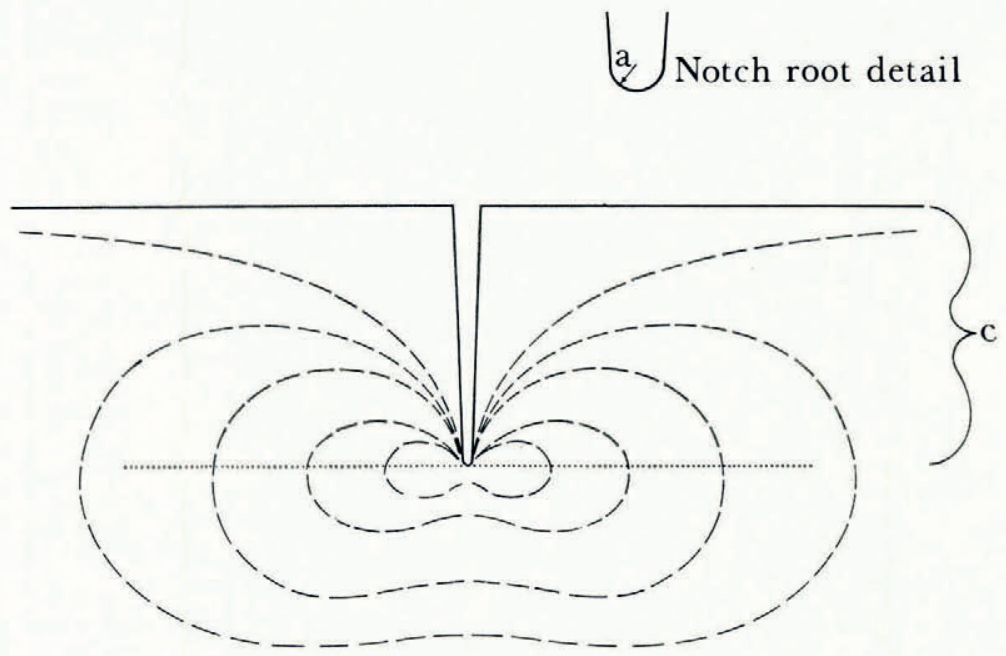

Fig. 2. A schematic representation of the stress concentration around a notch. The dashed lines are lines of constant tensile stress, the dotted line indicates a plane of high shear stress, $c$ is the notch length and $a$ is the notch root radius.

There are two further points which will be used later in the discussion. The first is that the stress concentration factor is sensitive to the pore size, and will therefore change as the notch propagates through different layers of snow. The second is that, even when the stress acting on the body is pure tension, once a notch starts there is a concentration of shear stress in the region of the notch root in the moving plane which includes the root and is perpendicular to the notch (dotted line in Figure 2, which is not, however, the plane of maximum shear stress). These points will be important when we consider the propagation of a notch through a layered snow-pack.

\section{SNOW-PAGK Model}

We can now apply these ideas to a somewhat idealized snow-pack and qualitatively develop a fracture mechanism. I will use a four-layer snow-pack described as follows (Fig. 3a): Each layer is homogeneous and isotropic. The surface layer (A) is of medium strength and density, perhaps wind toughened with network bonding characteristic of the middle stages of 
metamorphism. The next layer down (B) is a weaker layer of fairly low density that resulted from a cold snowfall without much wind. Layer $\mathrm{c}$ is a very thin, weak layer, highly metamorphosed, with large crystals and with very poor bonding to the lowest layer (D), an old, wind-toughened layer of high strength.

Because of the rapid propagation of cracks or notches in snow, the only stresses which are important at the instant of release are the elastic stresses. Downhill creep maintains these stresses against the action of plastic relaxation. A quantitative stress analysis even of our

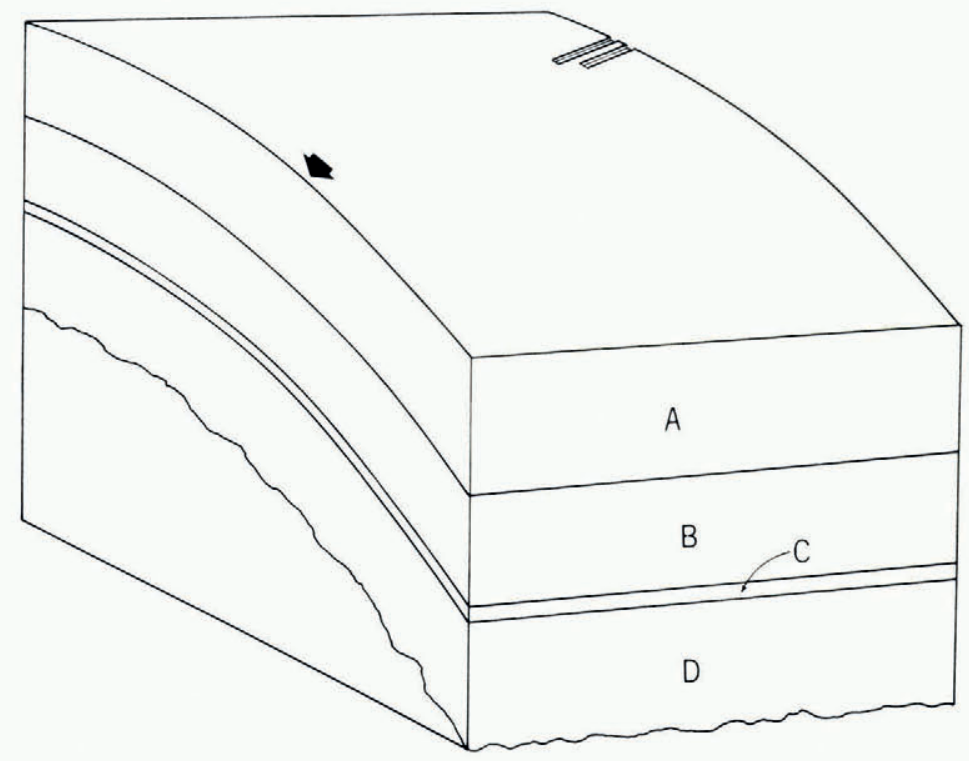

Fig. 3. (a) An idealized snow-pack as described in the text.

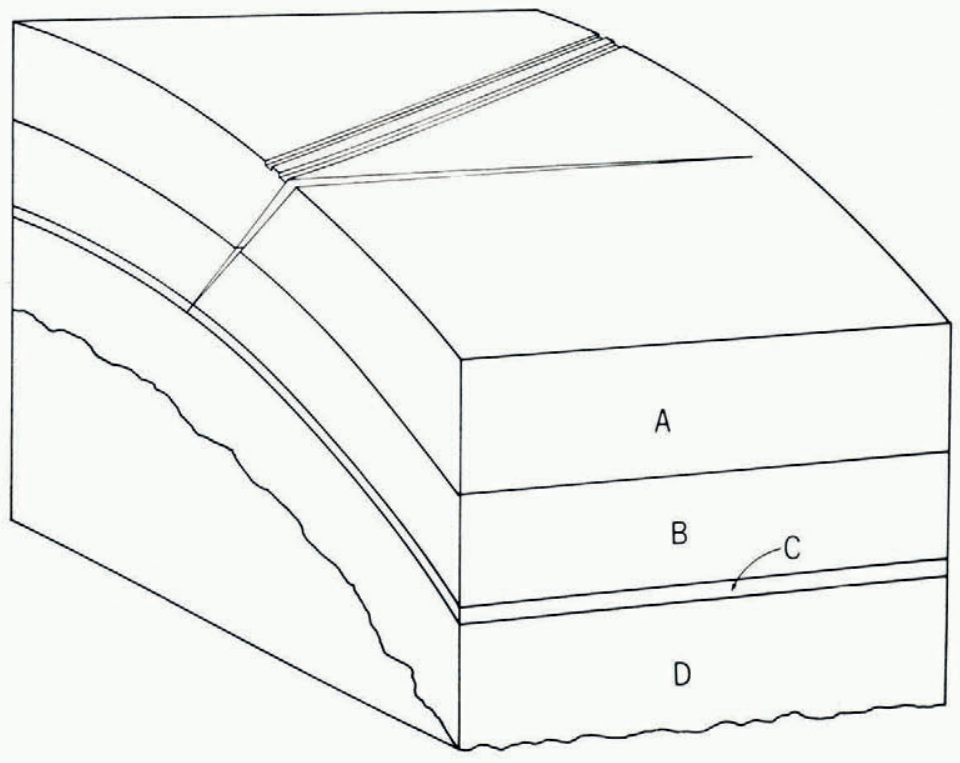

Fig. 3. (b) The initiation and propagation of the tension crack. 




Fig. 3. (c) The shear crack.

simplified model is beyond the scope of this paper. However, a qualitative description of the interaction of a propagating notch and the elastic energy released by failure will be sufficient to explain the proposed mechanism. The source of energy for crack propagation is the elastic stress which causes the snow layer to tend to contract either in one dimension parallel to the fall line or if the metamorphic volume change (Hobbs and Radke, r967) is not entirely relaxed by plastic flow, in two dimensions, parallel to the slope. The peripheral and basal anchorages restrain this contraction, causing stress concentrations at the periphery; in particular, high tensile stress at the upper, convex part of the slope (arrow in Fig. 3a). Once failure starts the snow is free to contract and the elastic energy thus released is dissipated in crack or notch propagation.

The weak layer might accentuate the development of elastic tensile stresses in the upper layers through faster creep caused by stress metamorphism. In a region of high temperature gradient, the transport of water vapor is relatively rapid, which promotes rapid metamorphism. When a layer is subjected to shear stress, the most highly strained bonds and crystals, being thermodynamically less stable, will disappear and the bonds and crystals under lower strain will grow. If the stress is maintained, however, the disappearance of the highly strained parts will transfer the stress to parts which were under lower strain. An increased rate of metamorphism under conditions of shear stress increases the creep rate, and it is possible that the major effect of the weak layer is to cause a higher rate of tension increase in the layers above.

In time, the tensile stress will increase to the point that a notch caused by a skier, for example, will propagate by stress concentration. Or if the snow is undisturbed, the stress will build to the point that some local flaw is large enough to propagate. In either case, the geometry of the stress concentration (Fig. 2) is such that a notch (started at or near the snow surface) will propagate downward, perpendicular to the surface. Since we are assuming that layers A, B and c are well bonded, the failure should easily propagate into and through layer B and into layer c (Fig. 3b). At layer c, however, three things can prevent further downward propagation. Probably the least important factor for most avalanches is that the grain size is larger, which lowers the stress concentration factor by increasing the notch root radius $a$. 
This will only be important in marginal cases. More important are the facts that the shear strength of layer $\mathrm{C}$ is very low and its bond to layer $\mathrm{D}$ also has a low shear strength. Then, since layer $\mathrm{D}$ is assumed to be strong, the shear strength at the boundary may not be large enough to cause layer D to break. For the notch to propagate, layer c must be strong enough, in shear, to pull the surface of layer $\mathrm{D}$ apart. If it is not, the failure will no longer propagate in tension but must propagate, if the remaining elastic tensile stress is high enough, in shear along the bottom of layer $\mathrm{C}$ as the upper layers contract elastically. This is shown (Fig. $3 \mathrm{c}$ ), with the vertical separation between $\mathrm{C}$ and $\mathrm{D}$ greatly exaggerated to illustrate the shear failure. Note that the shear failure should also propagate a short distance up-slope. If this up-slope failure finds a flaw or area of weak tensile strength in D, it could start a tensile failure in D (see Fig. 4). Layer c becomes the weak, well-lubricated, running surface. After the shear fracture has propagated down most of the slope, the snow, having no support, will fall.

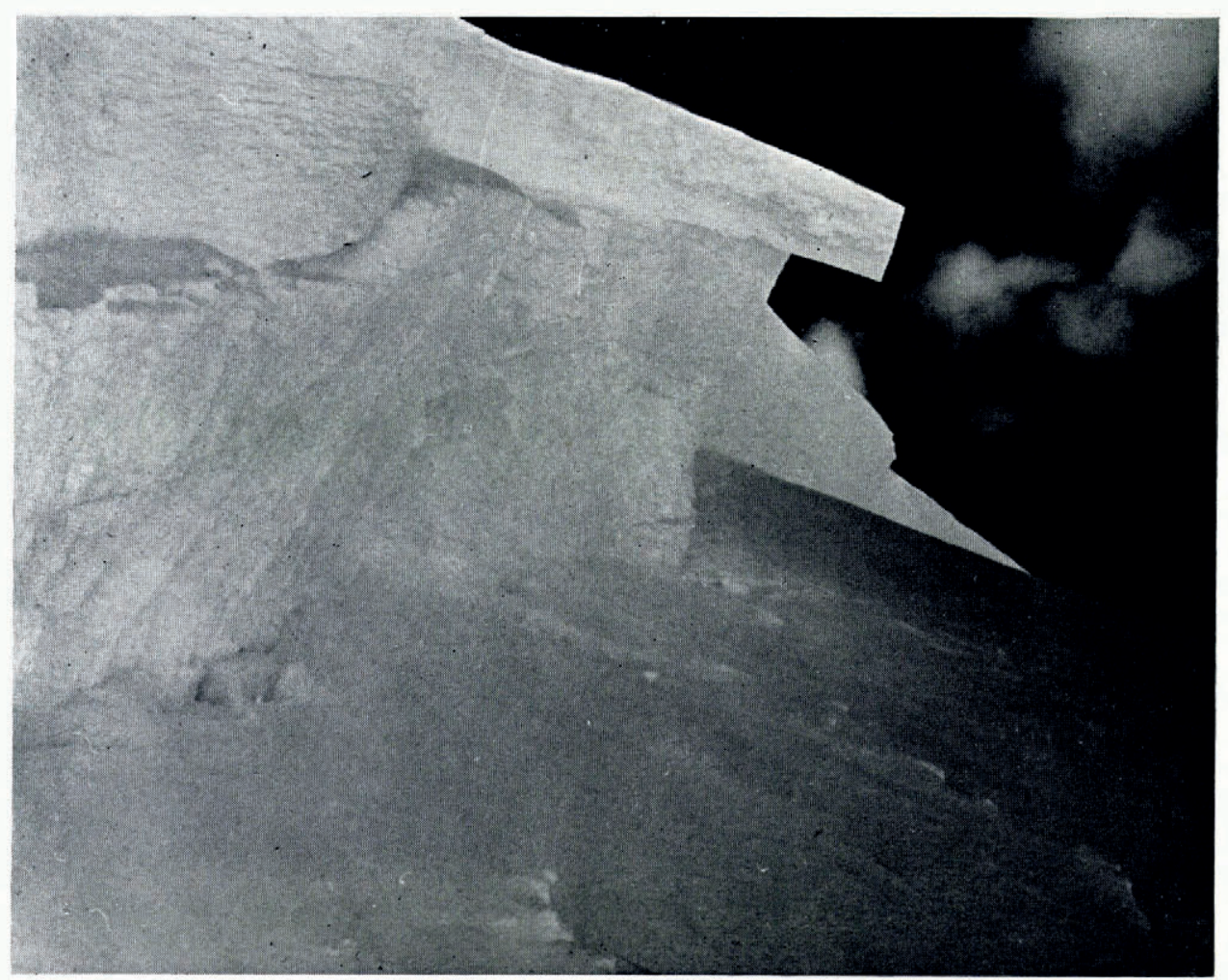

Fig. 4. An overhanging fracture line illustrating the up-slope propagation of the shear crack. (U.S. Forest Service photograph.)

\section{Conclusion}

The above mechanism has been presented without direct experimental proof. Because of the complexity of the problem, it is questionable whether it is possible to design definitive experiments to test the proposed mechanisms, and the proposed mechanisms must therefore be tested by attempting to use them to interpret the details of field observations.

It has been shown that snow, under slab avalanche conditions, acts as a brittle material. The mechanism proposed is consistent with current brittle-fracture theory and with the way brittle materials are known to fracture. Furthermore, it is more consistent with the observed 
actions of avalanches than mechanisms which depend on the failure of an internal layer for initiation.

Avalanches which "settle in place" are easily explained by this mechanism. Because of the stress concentration, a fracture may propagate when there is only a small average tensile stress built into the snow. Usually more than one tensile fracture will propagate and may entirely dissipate the elastic energy released by the contraction of the blocks which are formed. Then there will be no stress left for the propagation of a shear fracture, and the blocks will remain in place. When snow settles in place, the tension fractures which form usually are wider at the top than at the bottom. This detail would be very difficult to explain with an internal release mechanism.



Fig. 5. The mirror zone $(A)$, mist zone $(B)$ and hackle zone $(C)$ on the fracture face of a glass rod. (Photograph from 7 ohnson and Holloway (1968).)

If the situation is marginal for avalanche release, the lower stress concentration, because of the larger pore size, could cause the crack to propagate by starts and stops (crack arrest in fracture-mechanics terminology) which can result in a relatively low crack velocity for the shear failure. This mechanism would explain "hang-fire" avalanches. Alternatively, once the tension fractures are formed, delayed elasticity or accelerating creep (Mellor, I968) in an internal layer might release the snow after a short period of time.

Initiation by tension failure explains why avalanches are more easily released by disturbance of the zone of high tensile stress as opposed to the disturbance of other parts. Roch (1966) describes a case where an avalanche was released by a guide jumping on the high tension zone after two explosive charges, placed lower on the slope, failed to release the snow. 

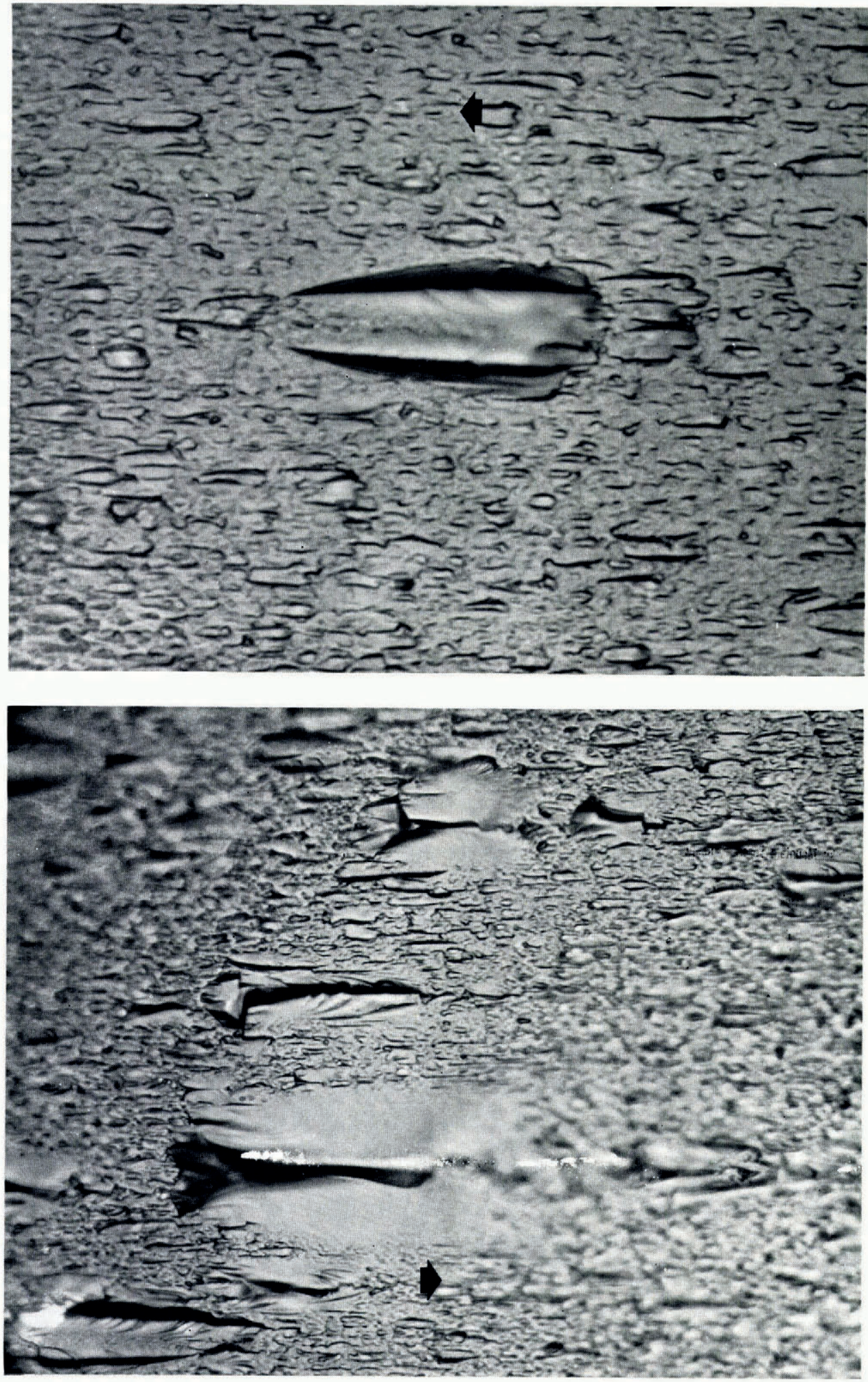

Fig. 6. Two types of mist zone features. Arrows show direction of crack propagation. (Photograph from Johnson and Holloway $(1968)$. 
The concept of stress concentration also explains why ski tracks are efficient in releasing avalanches.

We can gain further supporting evidence for tension failure initiation at the surface by examining fracture faces. The markings on some fracture faces show striking similarities to markings found on the fracture faces of glass and brittle plastics, but on a much larger scale. This might be explained by a geometrical analogy which can be drawn between snow and



Fig. 7. Parabolic features on a brittle fracture surface. Drawn from a figure in Kies and others (1950).

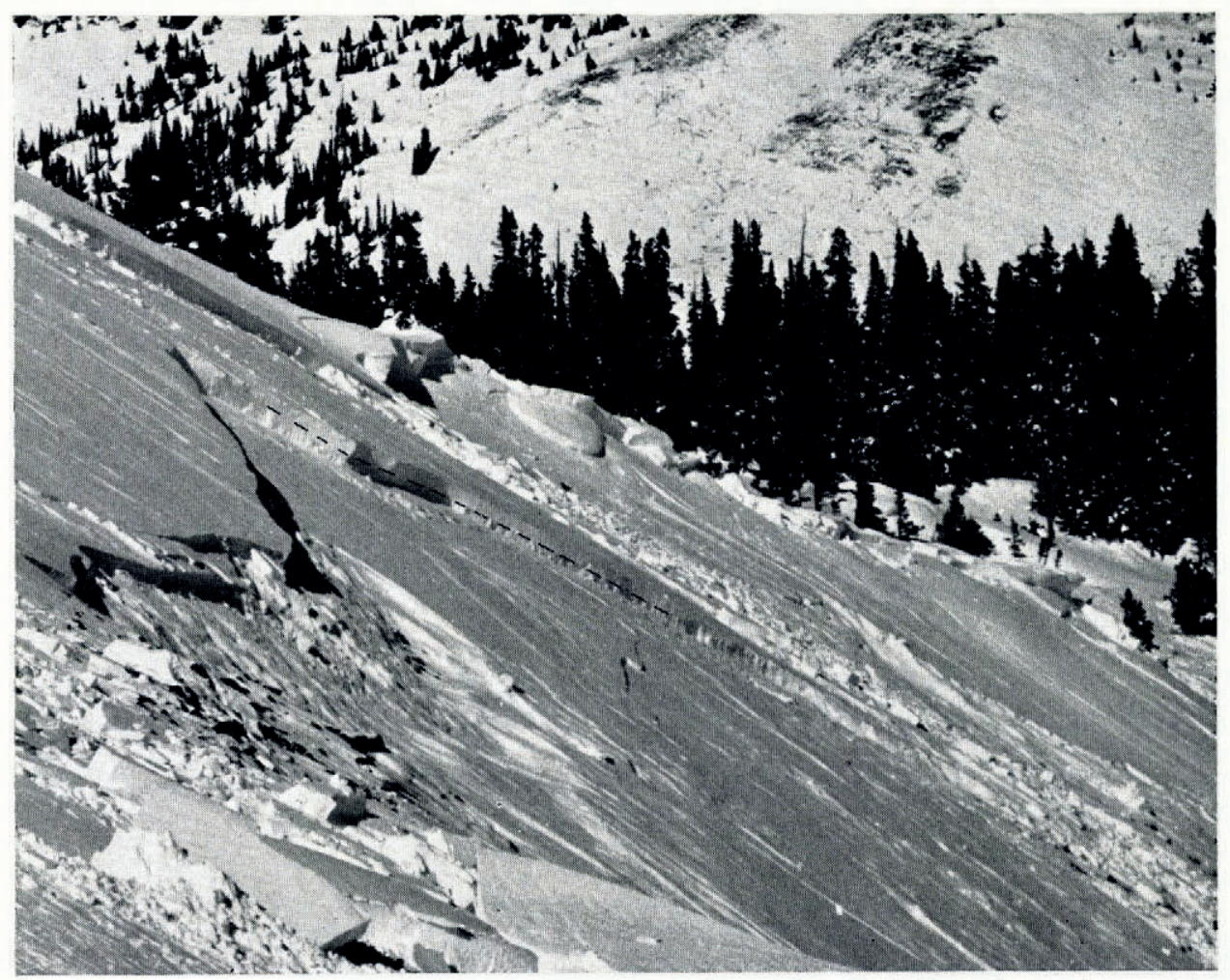

Fig. 8. The boundary of the mirror and mist zones on a snow fracture face. (U.S. Forest Service photograph.) 
glass or isotropic plastics with the snow grains corresponding to the atoms of the glass or the molecules of the plastic. Snow grains are bonded in a random, three-dimensional network as are the atoms and molecules of glass and plastics. The short-range order which exists in glass does not exist in snow but this should not have a strong effect on the fracture markings. This analogy is strictly geometrical and cannot be carried very far since the bonding laws of snow grains are very different from the bonding laws of atoms or molecules. At any rate many isotropic brittle solids exhibit similar fracture markings and the markings on glass fracture faces will serve as an example for comparison with snow. The initial fracture surface in glass called the "mirror zone", is smooth. This followed by the "mist zone" which has fine-grained features, and the "hackle zone" with much coarser features (Fig. 5, also see Andrews, I959).

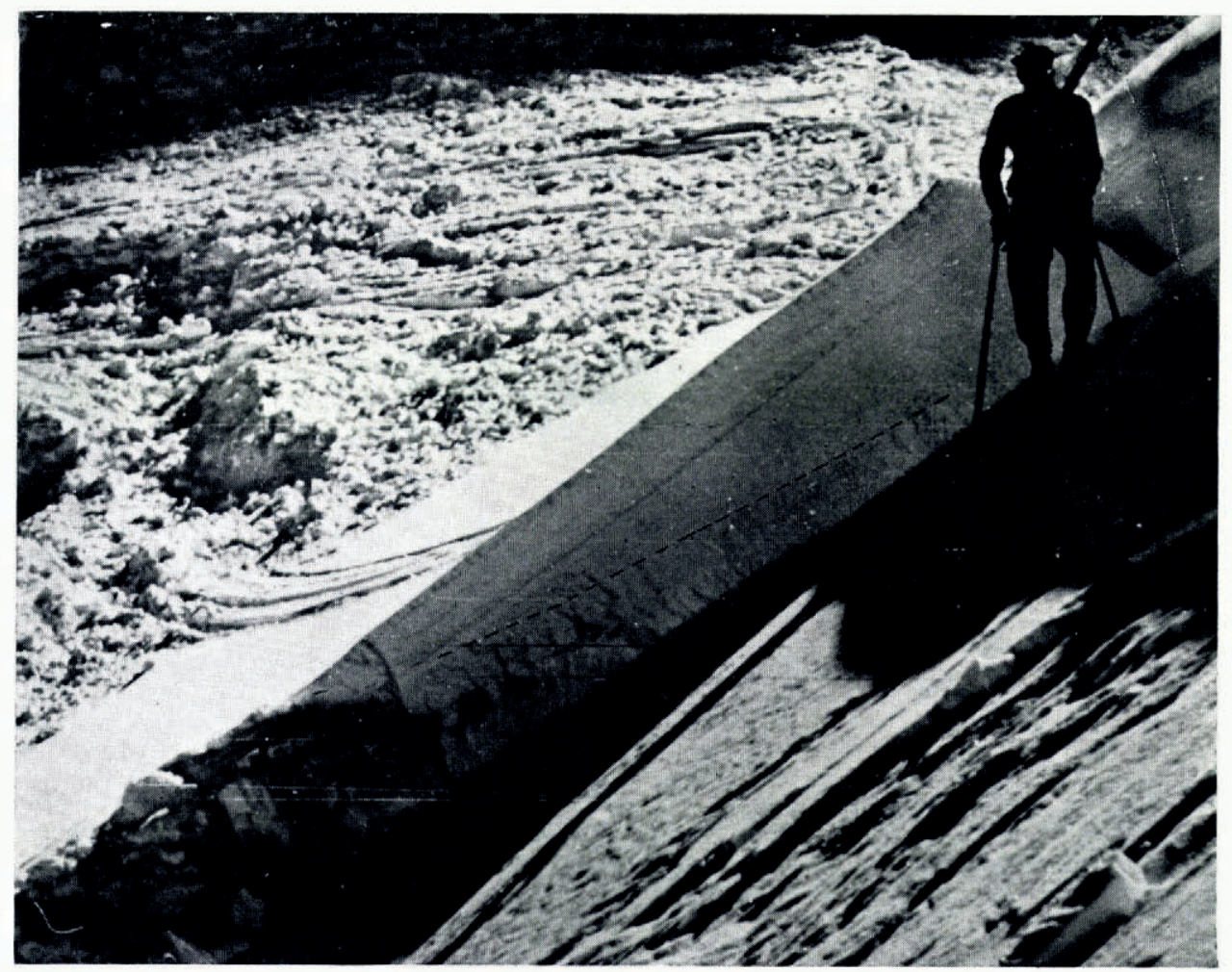

Fig. 9. The boundary of the mirror and mist zones on a snow fracture face. (Photograph by A. Roch.)

Johnson and Holloway (1968) have described features within the mist zone (Fig. 6), and Kies and others (1950) described certain parabolic features, commonly found on brittle fracture surfaces (Fig. 7). In general, these coarser features arise when the fracture has accelerated to a limiting velocity (theoretically o.6 times the transverse wave velocity). Then any additional elastic energy, instead of accelerating the fracture, causes local branching of the fracture front. The features (Figs. 5, 6 and 7) clearly indicate the direction of fracture propagation and the approximate point of fracture initiation. Figures 8 and 9 show the onset of coarser features very clearly, and a few cases of the parabolic features described by Kies and others (1950).

The fractures shown in these photographs were initiated at some point on the surface and propagated downward and outward. Thus, there is little doubt that the mechanism proposed 
above operates in some cases. The question which remains is whether or not it is the most common release mechanism. The answer to this question demands careful observation of the details of avalanche release. In particular, the following features should be noted:

(I) The shape of the fractures in snow which "settles in place" after the formation of tension fractures. Are they wider at the top or at the bottom?

(2) Does snow which "settles in place" actually settle? Are the two sides of each of the tension fractures at the same level or at different levels?

(3) Where does the tension fracture appear to start? If under ski release, does it start from the ski track or somewhere else?

(4) What is the shape and orientation of any parabolic or other irregularity on the face of the fracture?

\section{Acknowledgements}

I wish to thank D. G. Holloway and J. W. Johnson for supplying Figures 5, 6 and 7, and Taylor and Francis, Ltd., publishers of the Philosophical Magazine in which these figures first appeared, for their kind permission to use them. I also wish to thank A. Roch for Figure 9.

MS. received I November 1968

\section{REFERENGES}

Andrews, E. H. 1959. Strass waves and fracture surfaces. Fournal of Applied Physics, Vol. 30, No. 5, p. 740-43.

Bradley, C. C. I 666 . The snow resistograph and slab avalanche investigations. Union de Géodésie et Géophysique Internationale. Association Internationale d'Hydrologie Scientifique. Commission pour la Neige et la G'ace. Division Neige Saisonnière et Avalanches. Symposium international sur les aspects scientifiques des avalanches de neige, 5-10 avril 1965 , Davos, Suisse, p. $25^{1-60}$.

Bradley, C. C., and Bowle?, D. 1967. Strength-load ratio. An index of deep slab avalanche conditions. (In Oura, H., ed. Physics of snow and ice : international conference on low temperature science. ... $1966 . \ldots$ Proceedings, Vol. I, Pt. 2. [Sapporo], Institute of Low Temperature Science, Hokkaido University, p. 1 243-53.)

Bucher, E. 1947. Diskussionsbeitrag zum Lawinenverbau. Schweizerische Zeitschrift für Forstwesen, Jahrg. 98, Nr. I, p. I-22.

Bucher, E. 1948. Beitrag zu den theoretischen Grundlagen des Lawinenverbaus. Beiträge zur Geologie der Schweiz. Geotechnische Serie. Hydrologie, Lief. 6.

Griffith, A. A. I920. The phe.omena of rupture and flow in solids. Philosophical Transactions of the Royal Society of London, Ser. A, Vol. 22 1, Pt. 6, p. $163-98$.

Haefeli, R. 1942. Spannung;- und Plastizitätserscheinungen der Schneedecke. Schweizer Archiv für angewandte Wissenschaft und Technik, 8. Jahrg., Ht. 9-12, p. 263-74, 308-15, 349-58, 380-96; Mitteilungen aus der Versuchsanstalt für Wasserbau an der Eidg. Techn. Hochschule, Nr. 2, p. 45.

Haefeli, R. 1963 . Stress transformations, tensile strengths and rupture processes of the snow cover. (In Kingery, W. D., ed. Ice and snow; properties, processes, and applications: proceedings of a conference held at the Massachusetts Institute of Technology, February ${ }_{12-16}$, 1962 . Cambridge, Mass., The M.I.T. Press, p. 560-75.)

Hobbs, P. V., and Radke, L. F. 1967 . The role of volume diffusion in the metamorphism of snow. Fournal of Glaciology, Vol. 6, No. 48, p. 879-91.

Jaccard, C. I966. Stabilité des plaques de neige. Union de Géodésie et Géophysique Internationale. Association Internationale d'Hydrologie Scientifique. Commission pour la Neige et la Glace. Division Neige Saisonnière et Avalanches. Symposium international sur les aspects scientifiques des avalanches de neige, 5-10 avril 1965, Davos, Suisse, p. I70-81.

Johnson, J. W., and Holloway, D. G. 1968. Microstructure of the mist zone on glass fracture surfaces. Philosophical Magazine, Eighth Ser., Vol. i 7, No. r49, p. 899-9 го.

Kies, J. A., and others. 1950. Interpretation of fracture markings, by J. A. Kies, A. M. Sullivan and G. R. Irwin. Journal of Applied Physics, Vol. 21, No. 7, p. 716-20.

Kinosita, S. 1967. Compression of snow at constant speed. (In Oura, H., ed. Physics of snow and ice: international conference on low temperature science. . . . 1966. . . . Proceedings, Vol. I, Pt. 2. [Sapporo], Institute of Low Temperature Science, Hokkaido University, p. $9^{1}$ 1-27.)

McClintock, F. A., and Argon, A. S. 1966. Mechanical behavior of materials. Reading, Mass., Addison-Wesley Publishing Co.

Mellor, M. I968. Avalanches. U.S. Cold Regions Research and Engineering Laboratory. Cold regions science and engineering. Hanover, N.H., Pt. III, Sect. A3d.

Moskalev, Yu. D. I967. The stability of snow cover on mountain slopes. (In Oura, H., ed. Physics of snow and ice: international conference on low temperature science. . . 1966. . . Proceedings, Vol. 1, Pt. 2. [Sapporo], Institute of Low Temperature Science, Hokkaido University, p. 1215-22.)

Roch, A. 1966. Les déclenchements d'avalanches. Union de Géodésie et Géophysique Internationale. Association Internationale d'Hydrologie Scientifique. Commission pour la Neige et la Glace. Division Neige Saisonnière et Avalanches. Symposium international sur les aspects scientifiques des avalanches de neige, 5-10 avril 1965 , Davos, Suisse, p. 182-95. 